\title{
Thin-Film LSCs Based on PMMA Nanohybrid Coatings: Device Optimization and Outdoor Performance
}

\author{
S. M. El-Bashir, ${ }^{1,2}$ O. A. AlHarbi, ${ }^{1}$ and M. S. AlSalhi ${ }^{1}$ \\ ${ }^{1}$ Department of Physics and Astronomy, Science College, King Saud University, Riyadh 11451, Saudi Arabia \\ ${ }^{2}$ Department of Physics, Faculty of Science, Benha University, Benha 13518, Egypt
}

Correspondence should be addressed to S. M. El-Bashir; elbashireg@yahoo.com

Received 19 August 2013; Accepted 23 September 2013

Academic Editor: Maria da Graça P. Neves

Copyright (C) 2013 S. M. El-Bashir et al. This is an open access article distributed under the Creative Commons Attribution License, which permits unrestricted use, distribution, and reproduction in any medium, provided the original work is properly cited.

\begin{abstract}
This study concerns the design optimization of thin-film luminescent solar concentrators (TLSCs) based on polymethylmethacrylate (PMMA)/silica nanohybrid films doped with coumarin dyestuffs specialized in coloring plastics. Two designs of TLSCs had been prepared and characterized. The first consists of a transparent nanohybrid layer coated on a fluorescent PMMA substrate. The second design is the ordinary configuration in which fluorescent nanohybrid layer is coated on a transparent PMMA substrate. The investigation of the spectral properties and efficiency parameters recommended the best solar energy conversion efficiency for the second design. The outdoor performance of optimized TLSC was also evaluated under clear sky conditions of Riyadh city, and the hourly values of the optical efficiency, $\eta_{\text {opt }}$, were calculated for one year. The best performance was achieved in summer since the short circuit current for PV cell was doubled after being attached to TLSC and the value of $\eta_{\text {opt }}$ reached $40 \%$ which is higher than other values recorded before due to the abundant solar energy potential in the Arabian Peninsula.
\end{abstract}

\section{Introduction}

Concentrating sunlight is considered an important way to decrease the cost of photovoltaic (PV) energy conversion, since the cost of PV cell can be reduced by using concentrated sunlight on a smaller area. Luminescent solar concentrators (LSCs) were firstly proposed in the late 1970s as an alternative to the traditional focusing concentrators such as mirrors and lenses [1-4]. LSC consists of a transparent plate with a high refractive index (e.g., $\approx 1.49$ for PMMA), doped with centers as shown in Figure 1. When the incident light on the surface of LSC is absorbed by the luminescent centers and isotropically reemitted over all the angles, a fraction of light $(\approx 75 \%$ for PMMA) is internally reflected within the plate and guided towards the edges, where small photovoltaic (PV) cells can be placed to convert the concentrated light into electricity [5]. Diffuse reflecting paints can be placed on the nonused edges in order to improve light collection and geometrical gain which is defined as the fraction between surface and edge areas of LSC [6]. Since the collection of light is enhanced by total internal reflection, diffused sunlight has a higher probability of being collected and concentrated on PV cell. As a consequence, LSCs do not require light tracking systems, which represent an important and expensive component of conventional concentrating systems [7]. The interest of LSC research has recently been renewed due to the improvement in the stability of luminescent dyes and the development of new luminescent species such as quantum dots and inorganic alternative luminescent species [8]. This paper deals with the problems which hampered the development of LSCs such as the stability of luminescent organic dyes and the matrix configuration [9]. The first problem can be solved by using fluorescent dyes specialized in engineering plastics such as MACROLEX fluorescent dyes (Bayer, Germany); these dyes have been reported to have a promising thermal and photostability in LSC applications [10]. The second problem can be faced by thin-film LSC configuration (TLSC) shown in Figure 2 which was proposed to reduce the reabsorption of fluorescent photons and scattering losses. TLSC devices consist of a 0.15 to $1 \mathrm{~mm}$ thick layer of luminescent material deposited in a thicker transparent substrate $(\approx 30 \mathrm{~mm})$ ideally of the same refractive index [11]. Heavily doped luminescent 




FIGURE 1: The operation principle of luminescent solar concentration (LSC).



Design (1)



Design (2)

- Luminescent dye molecule

PV cell

(a)

(b)

FIgURE 2: Outline of the fabricated TLSC designs.

species can be doped in a transparent thin film and placed on a highly transparent substrate having the same refractive index for optical matching [12]. This configuration offers the possibility of reducing reabsorption effects by confining all the absorption and fluorescence to the thin film while trapping and reflection events occur primarily in the clear matrix [13]. TLSCs have several other advantages, as they allow the stacking of the plates containing different types of luminescent species to utilize full solar spectrum [14]. In addition, they reduce the fabrication cost as thin doped material is sufficient for allowing for more flexible employments of thin films with appropriate optical properties on any host substrate [15].

In the present study, we aimed to optimize the efficiency parameters of TLSCs by proposing two designs as depicted in Figure 2. Design (1) consists of a high refractive index transparent PMMA nanohybrid layer coated on a fluorescent PMMA substrate. Design (2) represents the ordinary design in which the luminescent dye is dissolved in PMMA nanohybrid layer then coated on a transparent PMMA substrate as previously described. A detailed characterization of the spectroscopic properties of the two designs will be presented by a series of measurements in order to identify the predominate losses limiting the efficiency parameters of TLSCs.

\section{Experimental}

2.1. Preparation of LSC Matrices. Hydrophilic nanosilica $\left(\mathrm{SiO}_{2}\right.$ Aldrich, $\mathrm{S} 5130$ powder, $\left.7 \mathrm{~nm}\right)$ was freed from adsorbed moisture by placing in an electric oven at $100 \pm 5^{\circ} \mathrm{C}$ and weighing each hour until two consecutive weights are the same. After that PMMA (Aldrich, MW $350 \mathrm{k}$ ), hydrophilic nanosilica, and red coumarin dyestuff (MACROLEX Fluorescent Red G, Bayer) were mixed separately in chloroform $\left(\mathrm{CHCl}_{3}\right)$. Transparent PMMA substrates were prepared by pouring 


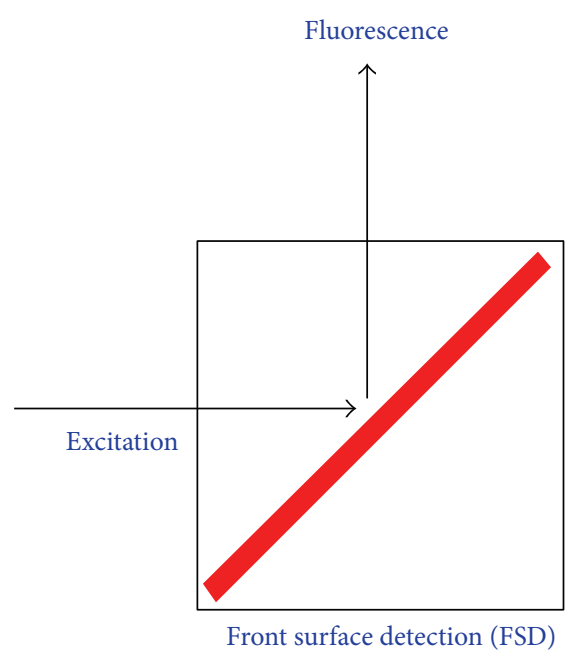

(a)



(b)

FIgURE 3: Excitation and detection arrangements of TLSC samples. (a) Front surface detection (FSD) (b) edge detection (ED).

$\mathrm{PMMA} / \mathrm{CHCl}_{3}$ solution in a rectangular glass mold; applying the same procedure fluorescent PMMA substrates were prepared by doping PMMA/ $\mathrm{CHCl}_{3}$ solution with $200 \mathrm{ppm}$ coumarin dyestuff. After that the dyed PMMA substrates were cut in dimensions $4 \times 1 \times 0.3 \mathrm{~cm}^{3}$ and then coated with $\mathrm{PMMA} / \mathrm{SiO}_{2}$ nanohybrids. Two groups for LSC designs were prepared. The first group (design 1) consists of fluorescent PMMA substrates coated by transparent $\mathrm{PMMA} / \mathrm{SiO}_{2}$ nanohybrid with nanosilica concentrations ranging from 0.05 to $1 \mathrm{wt} \%$. The second group (design 2) consists of transparent PMMA substrates coated by fluorescent PMMA/SiO nanohybrid with nanosilica concentrations ranging from 0.05 to $1 \mathrm{wt} \%$ and all doped with $200 \mathrm{ppm}$ coumarin dyestuff. All the hybrid solutions were sonicated for $6 \mathrm{hrs}$ before pouring on the as prepared substrates and spin coated in a centrifuge at $2000 \mathrm{rpm}$ for $1 \mathrm{~min}$ to obtain uniform film coverage [10]; then they were left to dry in an electric oven at $40^{\circ} \mathrm{C}$ for $6 \mathrm{hrs}$. The film thicknesses were measured using a profilometer (Talystep, Taylor Hobson, UK) on a scratch made immediately after deposition of five independent measurements [16] on each sample and found to be in the range of $50 \pm 10 \mu \mathrm{m}$.

2.2. Measurements. The absorption spectra of the hybrid films were recorded in the wavelength range (200-900 nm) by a UV-VIS spectrophotometer (UNICAM, Helios Co., Germany). Steady-state fluorescence spectra were recorded in the wavelength range (400-800 $\mathrm{nm})$ using a spectrofluorometer (SCHIMADZU RF-5301 PC, Japan); the spectra were recorded for two sample arrangements shown in Figure 3. The refractive index was measured by means of Abbe refractometer (ATAGO 1212 NAR-1T SOLID, Japan). The optimized LSC sample was chosen to manufacture a prototype for outdoor testing with dimensions of $20 \times 8 \times 0.3 \mathrm{~cm}^{3}$. A single crystalline silicon photodiode (PB X61, Siemens, Germany) was used as a PV cell and attached to one narrow edge as shown in Figure 2(b). The other LSC edges were painted with a diffuse reflecting paint which has a diffuse reflectance value of about 98\% (Kodak, Japan). LSC prototype was mounted horizontally and tested monthly for one year (2011) under day light illumination on the roof of a building about $(8 \mathrm{~m})$ high at Riyadh city $\left(37^{\circ} \mathrm{N}\right)$. The output short circuit current of LSC attached PV cell $\left(I_{\mathrm{Lsc}}\right)$ was measured along with that of the reference PV cell $\left(I_{\mathrm{rc}}\right)$ by using an accurate digital multimeter (PeakTech, Germany). Besides, the global solar radiation was measured using a digital solar power meter (Lutron SPM-1116 SD, Taiwan).

\section{Results and Discussion}

3.1. UV-Vis Optical Absorption Spectroscopy. Figure 4 shows the effect of nanosilica concentration on the UV-Vis absorption spectra for design (1) LSCs in the wavelength range (200-900 nm), which is a distinctive spectra PMMA doped with organic laser dyes $[17,18]$. A sharp increase of the absorption in the UVA band has been observed by increasing nanosilica concentration; this absorption is corresponding to $\pi-\pi^{*}$ transition of carbonyl groups in PMMA macromolecules [19]. It is observed that this increase is accompanied with a remarkable distortion and broadening in the absorption tail which is a consequence of a higher level of disorder of the polymer chains after bonding $\mathrm{C}=\mathrm{O}$ group with $\mathrm{Si}-\mathrm{OH}$ group. Considering the absorption band observed in the visible region around $520 \mathrm{~nm}$ characterizing $\mathrm{S}_{o} \rightarrow \mathrm{S}_{1}$ transition of the dye molecules, there is no major change observed in the absorption value due to the isolation of the dye molecules in PMMA matrix. The observed hyperchromic effect in the absorption spectra beyond $600 \mathrm{~nm}$ of design (1) samples can be attributed to the decrease of the sample transmission by increasing nanosilica concentration to about $79 \%$ of that of pure PMMA as clarified by the inset in Figure 4. This can be due to the light scattering by nanosilica aggregates as a result of the molecular bonding of silica nanoparticles with each other. 


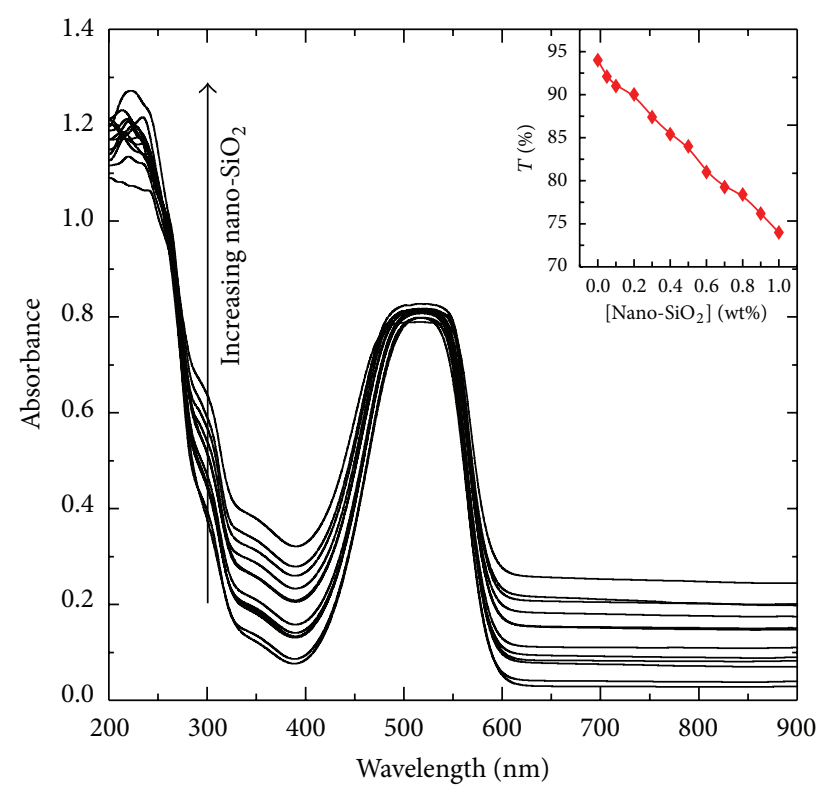

FIGURE 4: Effect of nanosilica concentration on the absorption and transmission (inset) spectra of design (1) TLSCs.

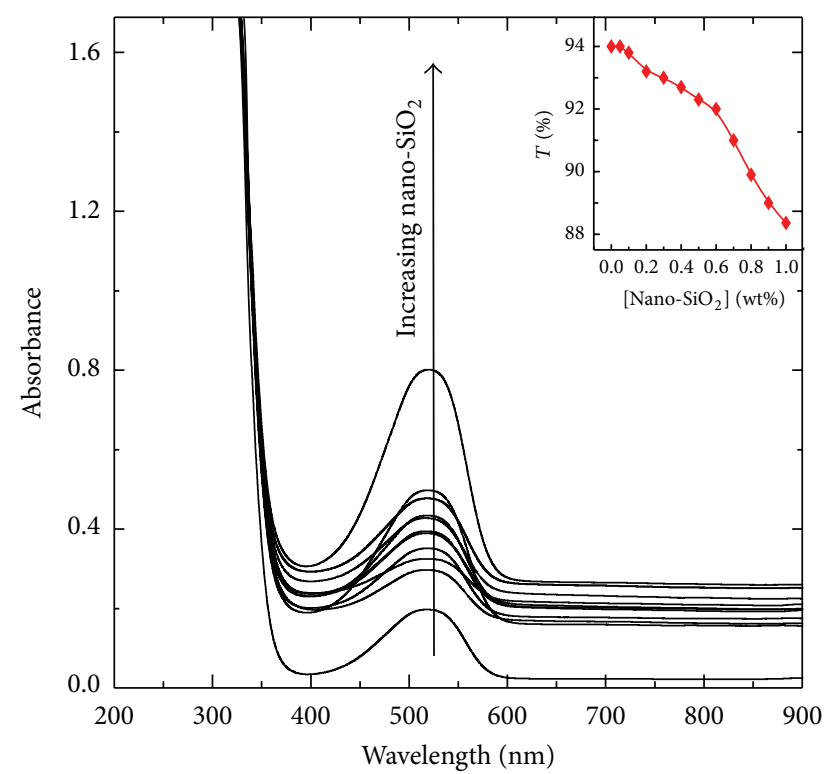

FIGURE 5: Effect of nanosilica concentration on the absorption and transmission (inset) spectra of design (2) TLSCs.

On the other hand for design (2) samples, Figure 5 illustrates that there are no significant changes observed in the absorption edge but there is an obvious increase in the dye absorption due to the chemisorption of coumarin molecules on the surface of silica nanoparticles through hydrogen bonding with surface silanol groups [20]. This bonding permits uniform dispersion of the dye molecules in undersized cores formed by $\mathrm{PMMA} / \mathrm{SiO}_{2}$ cages of the hybrid PMMA/ $\mathrm{SiO}_{2}$ network and subsequently decrease the probability of dye dimerization [21]. As shown by the inset in Figure 5, the sample transmission is observed to reach

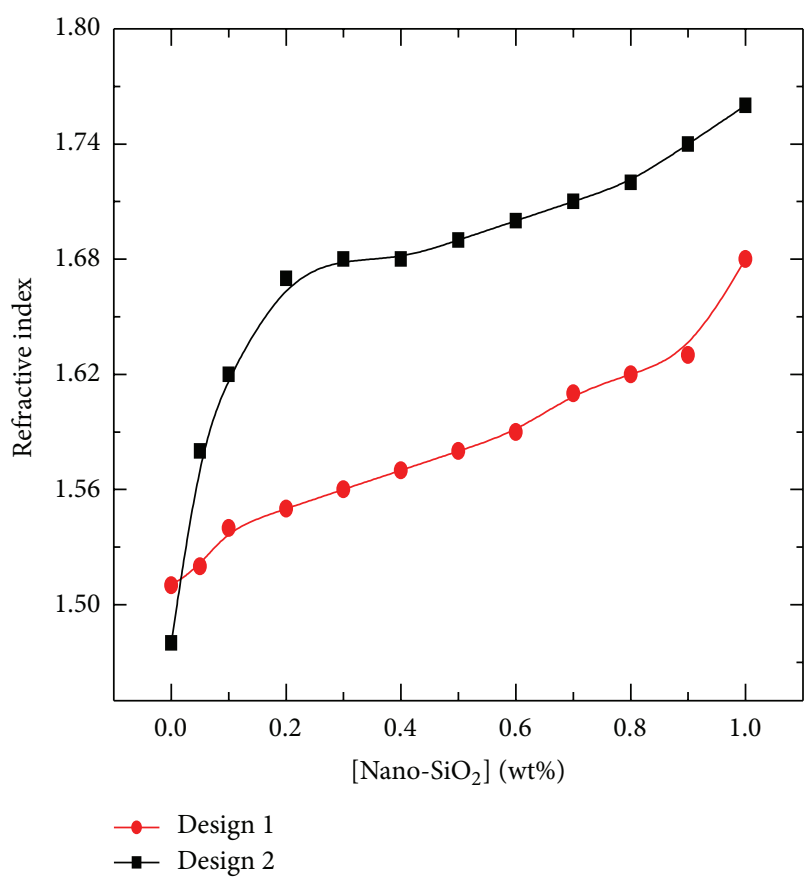

FIGURE 6: Effect of nanosilica concentration on the refractive index of TLSC designs.

about $94 \%$ of that for pure PMMA by increasing nanosilica concentration up to $1 \mathrm{wt} \%$; this indicates the advantage of this configuration for improving LSC transmission. This improvement can be attributed to the fact that the inclusion of dye molecules in $\mathrm{PMMA} / \mathrm{SiO}_{2}$ nanohybrids reduced the probability of nanosilica aggregate formation that occurs at high concentrations [22].

3.2. Refractive Index and Photon Trapping Efficiency. The dependence of the refractive index " $n$ " on the nanosilica concentration was studied for all the prepared samples of TLSC designs as shown in Figure 6. A remarkable increase is noted in the refractive index values for design (2) than those for design (1) TLSC samples. This can be attributed to the role played by coumarin dye molecules in reducing the aggregation of hydrophilic nanosilica in $\mathrm{PMMA} / \mathrm{SiO}_{2}$ nanohybrid film as confirmed by optical absorption spectroscopic measurements. It has been reasoned that the nanohybrid coating films for design (2) TLSC samples have more oriented structure than design (1) TLSC samples and consequently increased values of refractive index [23].

Photon trapping efficiency $\eta_{\text {trap }}$ was calculated from the refractive index $n$ of the films using the following equation [24];

$$
\eta_{\text {trap }}=\sqrt{1-\frac{1}{n^{2}}}
$$

The effect of nanosilica concentration on the values of $\eta_{\text {trap }}$ can be observed in Table 1; it is clear that the values of $\eta_{\text {trap }}$ for design (1) TLSC samples are lower than those of design (2). This disadvantage is expected when doping the dye 
TABLE 1: The effect of nanosilica concentration on the efficiency parameters (\%) $\eta_{\text {trap }}, \eta_{\varphi}$, and $\eta_{\text {stok }}$ for all TLSC designs.

\begin{tabular}{|c|c|c|c|c|c|c|}
\hline \multirow{2}{*}{ Concentration (wt\%) } & \multicolumn{3}{|c|}{ Design (1) } & \multicolumn{3}{|c|}{ Design (2) } \\
\hline & $\eta_{\text {trap }}$ & $\eta_{\varphi}$ & $\eta_{\text {stok }}$ & $\eta_{\text {trap }}$ & $\eta_{\varphi}$ & $\eta_{\text {stok }}$ \\
\hline 0 & 74.9 & 23.7 & 86.2 & 74.0 & 23.1 & 87.9 \\
\hline 0.05 & 75.4 & 23.9 & 86.2 & 77.3 & 25.8 & 88.2 \\
\hline 0.1 & 75.9 & 24.0 & 86.2 & 78.5 & 37.7 & 88.3 \\
\hline 0.2 & 76.5 & 24.3 & 86.2 & 79.9 & 41.8 & 88.7 \\
\hline 0.3 & 76.7 & 24.5 & 86.2 & 80.2 & 43.1 & 88.7 \\
\hline 0.4 & 77.0 & 24.6 & 86.2 & 80.3 & 44.6 & 88.7 \\
\hline 0.5 & 77.4 & 24.9 & 86.3 & 80.5 & 51.2 & 88.7 \\
\hline 0.6 & 77.9 & 25.4 & 86.3 & 80.7 & 58.1 & 88.7 \\
\hline 0.7 & 78.4 & 25.7 & 86.3 & 80.9 & 67.8 & 88.6 \\
\hline 0.8 & 78.6 & 25.9 & 86.3 & 81.2 & 77.2 & 88.6 \\
\hline 0.9 & 79.1 & 26.5 & 86.3 & 81.7 & 85.3 & 88.6 \\
\hline 1 & 80.3 & 27.1 & 86.26 & 82.1 & 91.0 & 90.0 \\
\hline
\end{tabular}

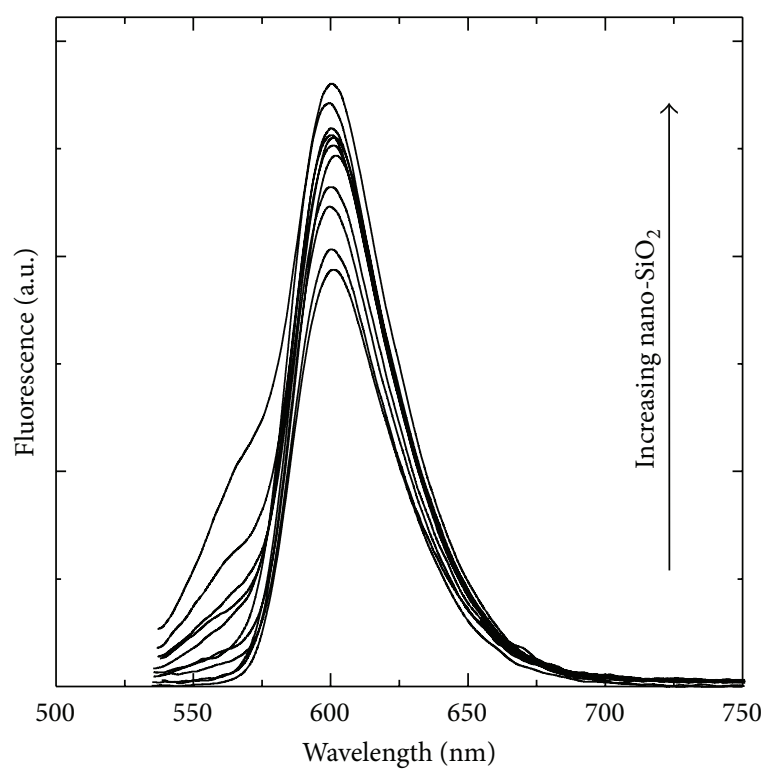

(a)

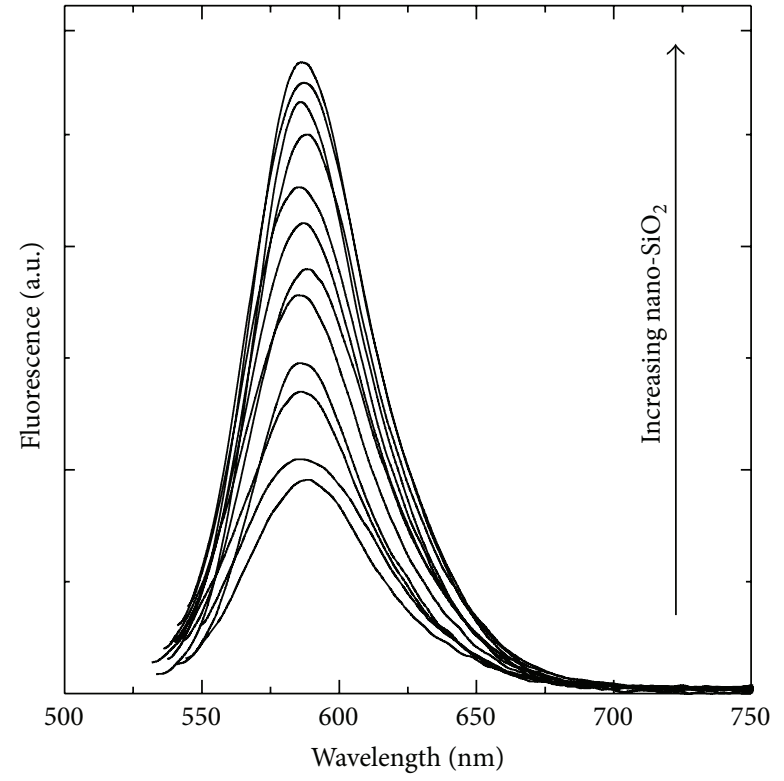

(b)

FIGURE 7: The effect of nanosilica concentration on the fluorescence spectra for (a) design (1) and (b) design (2) TLSCs.

molecules in bulk plate due to the scattering of fluorescent radiation by aggregated dye molecules, bulk matrix defects, and self-absorption effects [25].

3.3. Fluorescence Spectroscopy. Figure 7 shows the effect of nanosilica concentration on the fluorescence spectra of the prepared TLSC designs measured by using FSD. For design (1), it is observed that the fluorescence intensity is increased by increasing nanosilica concentration without any considerable change in the peak position; this can be ascribed to the increase of the number of fluorescent photons trapped in the LSC matrix. The shoulder that appeared in the spectra at higher nanosilica concentration may be correlated with the scattering of the trapped emitted photons with the matrix defects, causing the resultant broadening of fluorescence spectra [26]. The same behavior is observed for design (2) TLSCs with the exception of a remarkable blue shifted fluorescence and steadiness of the peak shape even at higher nanosilica concentrations. This can be due to two factors; the first is the isolation of the dye molecules by increasing nanosilica concentration causing blue shifted fluorescence [27] and the second is the increase of the fraction of trapped fluorescent radiation due to the increase of the refractive index and consequently increase of the trapped fluorescence intensity. The fluorescence quantum yield, $\eta_{\phi}$, has been calculated relative to a reference solution prepared from Rhodamine $101\left(\eta_{\phi r}=1\right.$ in $\left.\mathrm{H}_{2} \mathrm{O} 0.01 \% \mathrm{HCL}\right)$ using the following relation [28]:

$$
\eta_{\phi}=\eta_{\phi r}\left(\frac{D_{s}}{D_{r}}\right)\left(\frac{n_{s}}{n_{r}}\right)^{2}\left(\frac{1-10^{-\mathrm{OD}_{r}}}{1-10^{-\mathrm{OD}_{s}}}\right),
$$


where $D$ is the integrated area under the corrected fluorescence spectra, $n$ is the refractive index, and OD is the optical density for the sample and reference. Besides, the Stokes efficiency which represents the energy loss by Stokes shift was calculated as the ratio between the absorption and fluorescence maxima of dye molecules $\left(\eta_{\mathrm{stok}}=\lambda_{\mathrm{abs}} / \lambda_{\mathrm{em}}\right)$ [29]; the values of $\eta_{\phi}$ and $\eta_{\text {stok }}$ are listed in Table 1. It is obviously noted that the values of $\eta_{\phi}$ and $\eta_{\text {stok }}$ for design (1) TLSCs are lower than those of design (2); this can be explained by the following. Design (1) stands for PMMA matrix with large cores in which the dye molecules are just physically incorporated; at high dye concentrations the dye molecules have a large tendency to be aggregated in these cores and form excited state dimers (excimers) which are weakly fluorescent [30]. On the other hand, the calculated values of $\eta_{\phi}$ and $\eta_{\text {stok }}$ for design (2) demonstrate that the dye molecules are shown to have a relatively uniform dispersion in undersized cores formed by PMMA/SiO ${ }_{2}$ cages of the hybrid PMMA/SiO network. These solid cages have increased the separation between the dye molecules from each other and consequently the LSC coating can be heavily doped with high dye concentrations without quenching monomer (single dye molecule) fluorescence [31]. In view of the fact that the rotations and relaxations of the electrons in the excited state of organic laser dyes are one of the main modes of the nonradiative energy losses, $\mathrm{PMMA} / \mathrm{SiO}_{2}$ nanohybrid is a suitable matrix which reduces the internal rotational modes of the dye molecules compared to the relatively flexible organic polymer molecules [32].

3.4. Efficiency Parameters for Solar Energy Conversion. For the development of useful LSCs, it is important to use photostable dyes with a high overall dye efficiency, $\eta_{\text {dye }}$, given by [33]

$$
\eta_{\text {dye }}=\eta_{\text {abs }} \eta_{\phi} \eta_{\text {stok }} \eta_{\text {self }}
$$

where $\eta_{\mathrm{abs}}$ is the fraction of solar energy absorbed that depends on the absorption coefficient " $\alpha$ " of the dye and the LSC thickness " $d$ " ( $\left.\eta_{\text {abs }}=1-10^{-\alpha d}\right)[34]$ and $\eta_{\text {self }}$ accounts for the effect of the reabsorption of emitted photons on the light transport to the concentrator edge calculated from [35]

$$
\eta_{\text {self }}=\frac{P_{0}}{1-\left(1-P_{0} \eta_{\phi} \eta_{\text {trap }}\right)}
$$

where $P_{0}$ is the probability that an emitted the photon will reach the edge without suffering self-absorption calculated from

$$
P_{0}=\frac{\int P^{\prime}(v) E(v) d v}{\int E(v) d v},
$$

where the integrals $P^{\prime}(v) E(v) d v$ and $E(v) d v$ represent the areas under the fluorescence-wavenumber curves obtained from edge fluorescence detected by (ED) and front surface fluorescence (FSD), respectively, measured as depicted by Figure 3; the obtained spectra is plotted in Figure 8 as a representative behavior for all samples. The dependence of

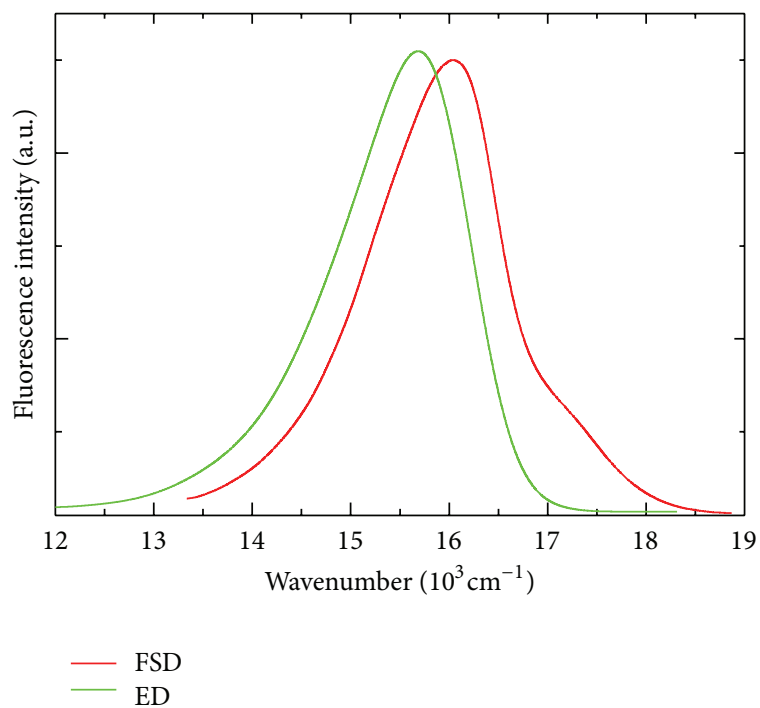

FIGURE 8: A representative plot of the wavenumber dependence of edge detected (ED) and front surface fluorescence (FSD) detecting fluorescence spectra measured for design (1) TLSC sample doped with $1 \mathrm{wt} \%$ nanosilica.

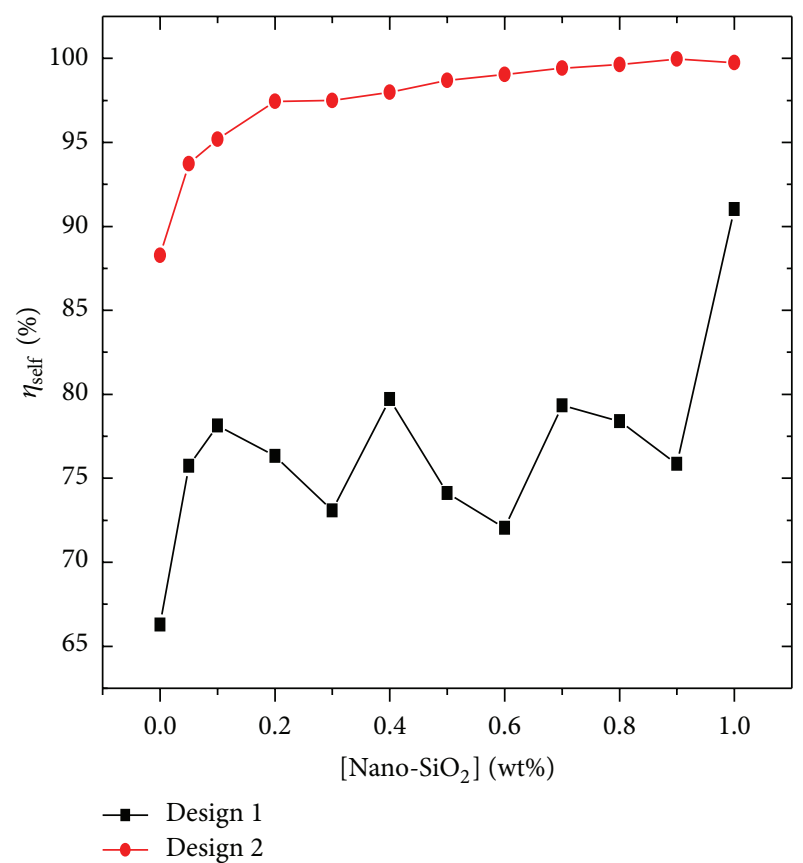

FIGURE 9: The dependence of self-absorption efficiency, $\eta_{\text {self }}$, on nanosilica concentration for TLSC designs.

self-absorption efficiency $\eta_{\text {self }}$, on nanosilica concentration is illustrated in Figure 9, it is obviously noted that design (1) TLSCs have low values of $\eta_{\text {self }}$ accompanied by irregular changes by increasing nanosilica concentration. On the other hand, the behavior of $\eta_{\text {self }}$ for design (2) exhibits a noticeable reduced self-absorption effect and scattering losses since the gain of the pathlength in the LSC substrate is compensated by the loss within the optically dense film [36]. 


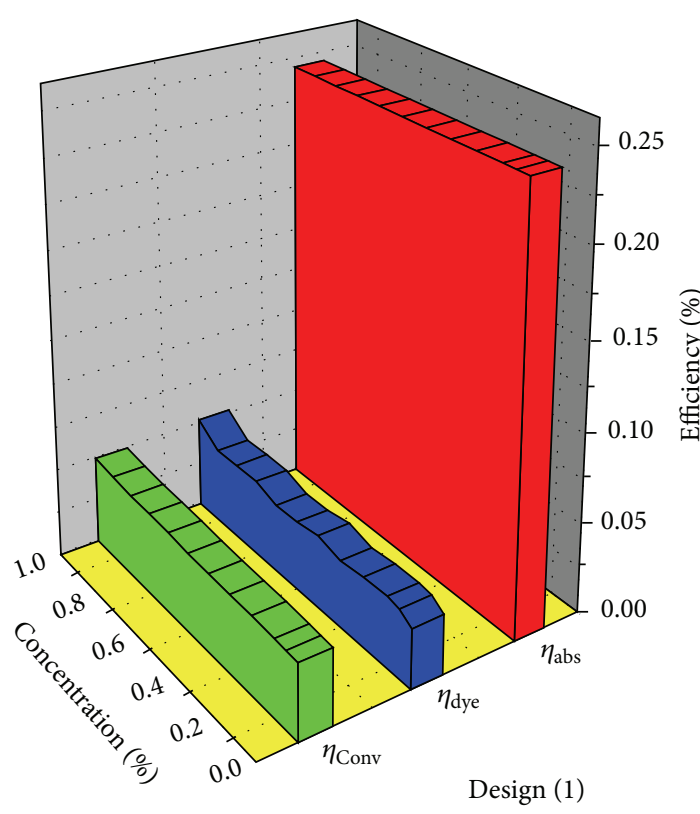

(a)

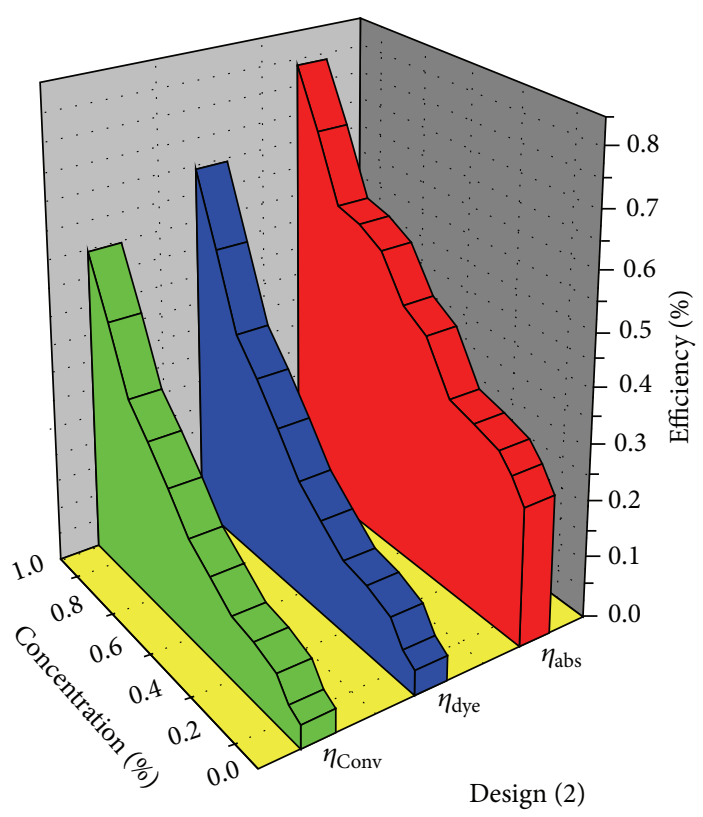

(b)

FIGURE 10: Effect of nanosilica concentration on the efficiency parameters of TLSC designs.

According to the photon flow diagram in LSCs, the conversion efficiency of the LSC, $\eta_{\text {conv }}$, which is defined as the ratio of the number of fluorescent photons " $N$ " available in the LSC to the number of the incident solar photons " $N_{o}$ " can be defined as [37]

$$
\eta_{\text {conv }}=\left(1-R_{f}\right) \eta_{\text {trap }} \eta_{\text {abs }} \eta_{\phi}=\frac{N}{N_{o}}
$$

where $\left(1-R_{f}\right)$ is the fraction of incident sunlight that is collected by the surface and calculated from Fresnel reflection $R_{f}=(n-1)^{2} /(n+1)^{2}$.

The effect of nanosilica concentration on the efficiency parameters $\eta_{\text {abs }}, \eta_{\text {dye }}$, and $\eta_{\text {conv }}$ is illustrated in Figure 10. For the prepared TLSC designs, it is clear that design (2) samples have higher efficiency parameters compared to design (1) samples. The highest increase in the efficiency parameters was achieved for design (2) TLSC doped with $1 \mathrm{wt} \%$ nanosilica concentration which is increased to 3,10 , and 11 times than those of design (1) TLSC for $\eta_{\mathrm{abs}}, \eta_{\text {dye, }}$, and $\eta_{\text {conv }}$, respectively. It is also observed that for the two designs, the values of $\eta_{\text {dye }}$ and $\eta_{\text {conv }}$ have the same behavior of $\eta_{\text {abs }}$ with varying nanosilica concentration. This reveals the advantage of design (2) in increasing the fraction of absorbed sunlight and enhancing solar energy conversion by TLSCs. The highest calculated values of conversion efficiency for the prepared TLSC designs had allowed the choice of design (2) $\left(\eta_{\text {conv }}=\right.$ $55 \%$ ) to be tested outdoors for electrical conversion of solar energy.

3.5. Field Performance of TLSC. The average daily solar insolation on a horizontal surface $P_{G}$ was measured hourly for one year (Riyadh, 2011) and plotted as shown in Figure 11. It is noticed that the curve of global solar radiation versus day

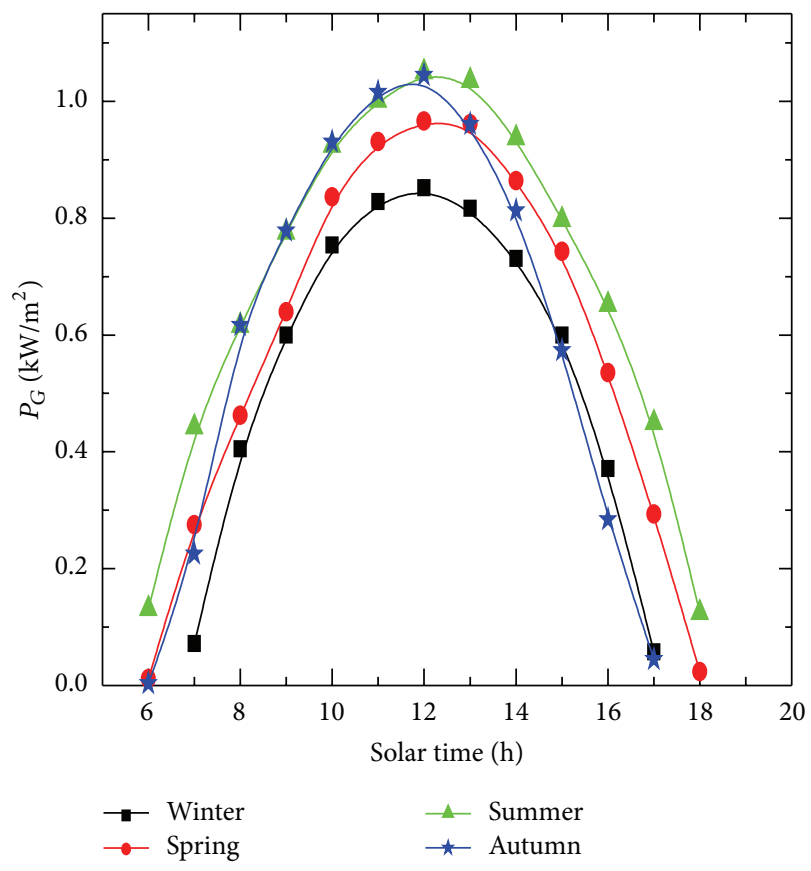

FIGURE 11: The hourly distribution of the global solar energy radiation in Riyadh city over the year 2011.

hours has reached its maximum value at the solar noon for all seasons with a highest value equal to $1 \mathrm{~kW} / \mathrm{m}^{2}$ achieved in summer. This data is important for the properly design of solar energy system [38] and provides a good evaluation of thermal environment within buildings in hot countries which is characterized by its extremely hot weather. 


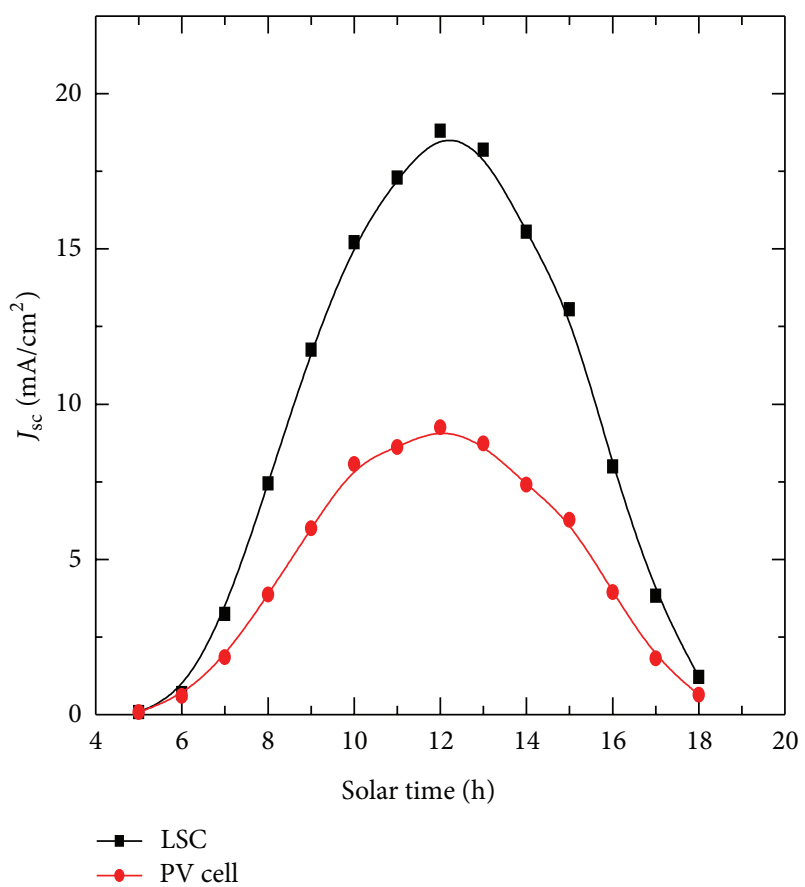

FIGURE 12: The average values of the short circuit current density, $J_{\mathrm{sc}}$, over the year 2011.

Figure 12 illustrates the average values of the short circuit current density, $J_{\mathrm{sc}}$, over the year 2011 for the PV cell attached to the TLSC edge mounted horizontally as shown in Figure 2. It is noted that the maximum values of $J_{\mathrm{sc}}$ are obtained around the solar noon of each season, due to the increase of direct solar radiation at this time. The area under the $J_{\mathrm{sc}}$-solar time curves is obtained and plotted in comparison with that of a reference PV cell for all seasons as shown in Figure 13. It is clear that the maximum value of the obtained electric charge by TLSC is obtained in summer $\left(621 \mathrm{C} / \mathrm{cm}^{2}\right)$. This value is more than twice that recorded for horizontal bulk plate LSC in Benha city (Egypt) due to the fact that Riyadh city enjoys higher solar insolation [39]. This high amount of global solar energy in Riyadh compared to Benha is caused by the increase of the direct component due to the variations in solar altitude and the zenith angle. On the other hand, it is noted that the minimum value of electric charge $\left(162 \mathrm{C} / \mathrm{cm}^{2}\right)$ is obtained in spring due to the vagaries of the weather and the spread of dust and clouds at this time of the year.

The performance of the investigated TLSC was evaluated under clear sky conditions, and the hourly values of the optical efficiency $\eta_{\text {opt }}$ were calculated for all seasons using the following equation [40]:

$$
\eta_{\mathrm{opt}}=\left(\frac{I_{\mathrm{sc}}}{I_{\mathrm{ref}}}\right)\left(\frac{B}{G}\right),
$$

where $I_{\mathrm{sc}}$ and $I_{\mathrm{rc}}$ are the short circuit currents of the PV cells attached to TLSC edge and the reference PV cells directly exposed to sunlight, respectively, $G$ is the geometric gain defined as the ratio of the surface area to the edge area of the TLSC plate, and $B$ is the ratio of PV cell response at



FIGURE 13: The area under the $J_{\text {sc }}$-solar time curves obtained of TLSC and plotted in comparison with that of a reference PV cell for all seasons (Riyadh-2011).

the fluorescence wavelength to the corresponding response of solar spectra.

Figure 14 demonstrates a plot of the hourly values of $\eta_{\mathrm{opt}}$ for the investigated TLSC, and the seasonal average values of $\eta_{\text {opt }}$ and $I_{\text {sc }} / I_{\text {ref }}$ are listed in Table 2. From the plot, it is clear that the yearly average value of $\eta_{\text {opt }}$ increases at the midday to a stationary value for $8 \mathrm{hrs}$; then decreases near both the sunrise and sunset in contrast to the previously published work $[41,42]$. This can be due to the fact that most of the solar radiation in Riyadh is direct due to its high altitude angle, since the global solar radiation falling on a horizontal surface is given by [43]

$$
P_{G}=P_{D}+P_{B} \sin \gamma
$$

where $P_{D}$ is the diffused solar radiation, $P_{B}$ is the direct (beam) component and $\gamma$ is the solar altitude angle of the location. The decrease of the yearly average value of $\eta_{\text {opt }}$ near the sunset and sunrise can be attributed to low amount of diffused radiation as a result of the high clearness index $K_{T}$ in Riyadh [44] at most of the year months according to the following equation $[45,46]$,

$$
\frac{P_{D}}{P_{G}}=1-1.13 K_{T} .
$$

Furthermore, Table 2 shows that summer average value of $\eta_{\text {opt }}$ is nearly double that published for horizontal bulk LSC in Egypt (23.61\%). This can be attributed to the advantage of TLSCs in reducing the parasitic losses due to self-absorption and scattering from matrix impurities than bulk LSCs besides the abundant solar energy potential in the Arabian Peninsula [47]. 


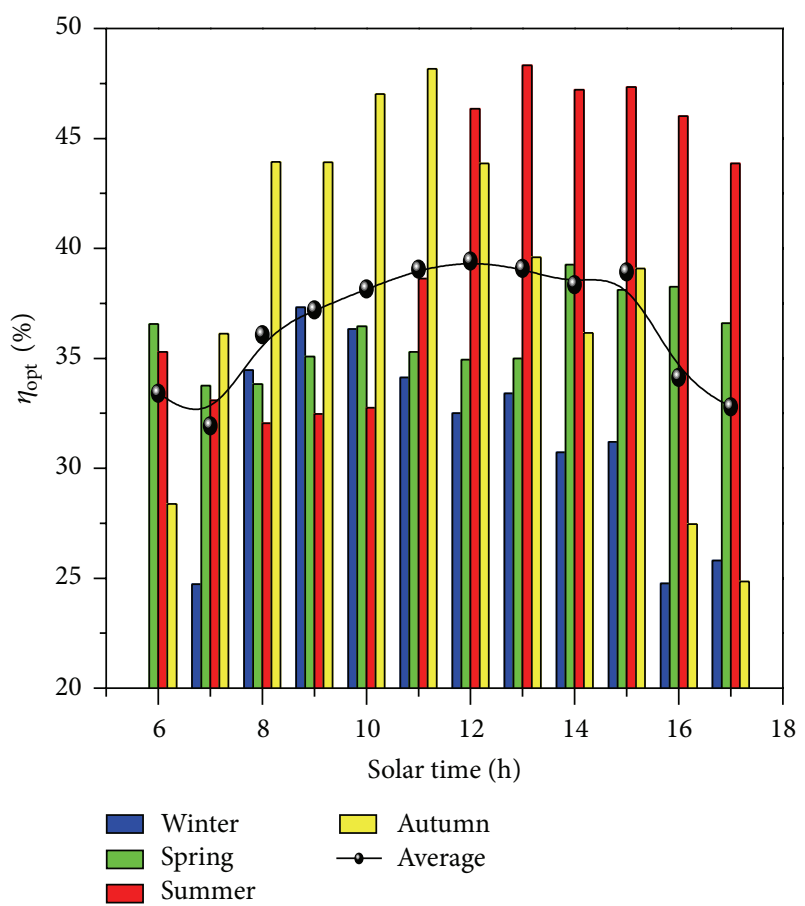

FIgURE 14: The hourly distribution of the optical efficiency, $\eta_{\text {opt }}$, for TLSC (Riyadh-2011).

TABLE 2: The average values of $\eta_{\mathrm{opt}}$ and $I_{\mathrm{sc}} / I_{\text {ref }}$ for horizontally mounted TLSC for one year (Riyadh, 2011).

\begin{tabular}{lcc}
\hline Season & $\eta_{\mathrm{opt}} \%$ & $I_{\mathrm{sc}} / I_{\text {ref }}$ \\
\hline Winter & 31.40 & 1.744 \\
Spring & 36.10 & 2.005 \\
Summer & 40.28 & 2.240 \\
Autumn & 38.21 & 2.123 \\
\hline Yearly average & 36.82 & 2.045 \\
\hline
\end{tabular}

\section{Conclusions}

Two designs of TLSCs have been prepared and characterized in order to optimize the efficiency parameters and outdoor performance. The study of UV-Vis absorption indicated that all the prepared samples of TLSC designs utilize a broad section of the solar spectrum. In addition, calculated values of efficiency parameters suggested that design (2) is more advantageous since it has the lowest reabsorption, possibility of escape cone losses, and the highest conversion efficiency. The study of outdoor performance of the optimized design (2) TLSC showed the maximum recorded value of $\eta_{\text {opt }}(\approx 40 \%)$. Regarding the above-mentioned facts, it can be stated that design (2) TLSCs are potential candidates for solar energy conversion the in the Arabian Peninsula. Further studies of the molecular and photostability tests had to be done, since the second design is expected to show a distinctive photostability due to the existence of the dye molecules in the lower PMMA substrate protected by $\mathrm{PMMA}^{-\mathrm{SiO}_{2}}$ nanohybrid coating which is considered as an effective solution for blocking harmful UV radiation. Thus, the low efficiency of the second TLSC design could be compensated by their application in large areas, especially in the vast desert areas of hot countries which need conversion systems with enhanced photostability.

\section{Acknowledgment}

This research project was supported by a grant from the Research Center of the Female Scientific and Medical Colleges, Deanship of Scientific Research, King Saud University.

\section{References}

[1] W. H. Weber and J. Lambe, "Luminescent greenhouse collector for solar radiation," Applied Optics, vol. 15, no. 10, pp. 22992300, 1976.

[2] J. S. Batchelder, A. H. Zewail, and T. Cole, "Luminescent solar concentrators. 1: theory of operation and techniques for performance evaluation," Applied Optics, vol. 18, no. 18, pp. 3090-3110, 1979.

[3] A. Goetzberger and W. Greube, "Solar energy conversion with fluorescent collectors," Applied Physics, vol. 14, no. 2, pp. 123139, 1977.

[4] R. Reisfeld, "Future technological applications of rare-earthdoped materials," Journal of The Less-Common Metals, vol. 93, no. 2, pp. 243-251, 1983.

[5] M. G. Debije, "Solar energy collectors with tunable transmission," Advanced Functional Materials, vol. 20, no. 9, pp. 14981502, 2010.

[6] W. G. J. H. M. van Sark, "Luminescent solar concentrators: a low cost photovoltaics alternative," Renewable Energy, vol. 49, pp. 207-210, 2013.

[7] A. Goetzberger, "Fluorescent solar energy collectors: operating conditions with diffuse light," Applied Physics, vol. 16, no. 4, pp. 399-404, 1978.

[8] J. Bomm, A. Büchtemann, A. J. Chatten et al., "Fabrication and full characterization of state-of-the-art quantum dot luminescent solar concentrators," Solar Energy Materials and Solar Cells, vol. 95, no. 8, pp. 2087-2094, 2011.

[9] B. C. Rowan, L. R. Wilson, and B. S. Richards, "Advanced material concepts for luminescent solar concentrators," IEEE Journal on Selected Topics in Quantum Electronics, vol. 14, no. 5, pp. 1312-1322, 2008.

[10] S. M. El-Bashir, F. M. Barakat, and M. S. AlSalhi, "Metalenhanced fluorescence of mixed coumarin dyes by silver and gold nanoparticles: towards plasmonic thin-film luminescent solar concentrator," Journal of Luminescence, vol. 143, pp. 43-49, 2013.

[11] J. W. E. Wiegman and E. Van der Kolk, "Building integrated thin film luminescent solar concentrators: detailed efficiency characterization and light transport modelling," Solar Energy Materials and Solar Cells, vol. 103, pp. 41-47, 2012.

[12] G. Griffini, L. Brambilla, M. Levi, M. D. Zoppo, and S. Turri, "Photo-degradation of a perylene-based organic luminescent solar concentrator: molecular aspects and device implications," Solar Energy Materials amd Solar Cells, vol. 111, pp. 41-48, 2013.

[13] P. T. M. Albers, C. W. M. Bastiaansen, and M. G. Debije, "Dual waveguide patterned luminescent solar concentrators," Solar Energy, vol. 95, pp. 216-223, 2013.

[14] A. A. Earp, G. B. Smith, J. Franklin, and P. Swift, "Optimisation of a three-colour luminescent solar concentrator daylighting 
system," Solar Energy Materials and Solar Cells, vol. 84, no. 14, pp. 411-426, 2004.

[15] R. Reisfeld, "New developments in luminescence for solar energy utilization," Optical Materials, vol. 32, pp. 850-865, 2010.

[16] A. Pepe, P. Galliano, M. Aparicio, A. Durán, and S. Ceré, “Sol-gel coatings on carbon steel: electrochemical evaluation," Surface and Coatings Technology, vol. 200, no. 11, pp. 3486-3491, 2006.

[17] A. F. Mansour, M. G. El-Shaarawy, S. M. El-Bashir, M. K. El-Mansy, and M. Hammam, "Optical study of perylene dye dopedpoly(methyl methacrylate) as fluorescent solar collector," Polymer International, vol. 51, no. 5, pp. 393-397, 2002.

[18] D. Avnir, D. Levy, and R. Reisfeld, "The nature of the silica cage as reflected by spectral changes and enhanced photostability of trapped rhodamine 6G," Journal of Physical Chemistry, vol. 88, no. 24, pp. 5956-5959, 1984.

[19] M. Hammam, M. K. El-Mansy, S. M. El-Bashir, and M. G. ElShaarawy, "Performance evaluation of thin-film solar concentrators for greenhouse applications," Desalination, vol. 209, no. 1-3, pp. 244-250, 2007.

[20] Y. Huang, X. Y. Ma, G. Z. Liang, and H. X. Yan, "Interactions in organic rectorite composite gel polymer electrolyte," Clay Minerals, vol. 42, no. 4, pp. 463-470, 2007.

[21] D. Levy, R. Reisfeld, and D. Avnir, "Fluorescence of Europium(III) trapped in silica gel-glass as a probe for cation binding and for changes in cage symmetry during gel dehydration," Chemical Physics Letters, vol. 109, pp. 593-597, 1984.

[22] R. Reisfeld, N. Manor, and D. Avnir, “Transparent high surface area porous supports as new materials for luminescent solar concentrators," Solar Energy Materials, vol. 8, no. 4, pp. 399409, 1983.

[23] V. Švorčík, O. Lyutakov, and I. Huttel, “Thickness dependence of refractive index and optical gap of PMMA layers prepared under electrical field," Journal of Materials Science, vol. 19, no. 4, pp. 363-367, 2008.

[24] J. Roncali and F. Garnier, "Photon-transport properties of luminescent solar concentrators: analysis and optimization," Applied Optics, vol. 23, no. 16, pp. 2809-2817, 1984.

[25] R. W. Olson, R. F. Loring, and M. D. Fayer, "Luminescent solar con-centrators and the reabsorption problem," Applied Optics, vol. 20, no. 17, pp. 2934-2939, 1981.

[26] S. A. Ahmed, Z. Zang, K. M. Yoo, M. A. Ali, and R. R. Alfano, "Effect of multiple light scattering and self-absorption on the fluorescence and excitation spectra of dyes in random media," Applied Optics, vol. 33, no. 13, pp. 2746-2750, 1994.

[27] K. Unger, Porous Silica, Elsevier, New York, NY, USA, 1979.

[28] S. Fery-Forgues and D. Lavabre, "Are fluorescence quantum yields so tricky to measure? A demonstration using familiar stationery products," Journal of Chemical Education, vol. 76, no. 9, pp. 1260-1264, 1999.

[29] F. P. Shäfer, Dye Lasers, Springer, New York, NY, USA, 1990.

[30] J. F. Rabek, Experimental Methods in Polymer Chemistry, John Wiley \& Sons, New York, NY, USA, 1980.

[31] A. M. Hermann, "Luminescent solar concentrators-a review," Solar Energy, vol. 29, no. 4, pp. 323-329, 1982.

[32] S. M. El-Bashir, "Photophysical properties of fluorescent PMMA/ $\mathrm{SiO}_{2}$ nanohybrids for solar energy applications," Journal of Luminescence, vol. 132, no. 7, pp. 1786-1791, 2012.

[33] F. Vollmer and W. Rettig, "Fluorescence loss mechanism due to large-amplitude motions in derivatives of $2,2^{\prime}$-bipyridyl exhibiting excited-state intramolecular proton transfer and perspectives of luminescence solar concentrators," Journal of Photochemistry and Photobiology A, vol. 95, no. 2, pp. 143-155, 1996.

[34] S. M. El-Bashir, Photophysical Properties of PMMA Nanohybrids and Their Applications: Luminescent Solar Concentrators \& Smart Greenhouses, Book Project, LAMPERT Academic Publishing, 2012.

[35] J. M. Drake, M. L. Lesiecki, J. Sansregret, and W. R. L. Thomas, "Organic dyes in PMMA in a planar luminescent solar collector: a performance evaluation," Applied Optics, vol. 21, no. 16, pp. 2945-2952, 1982.

[36] A. Hinsch, A. Zastrow, and V. Wittwer, "Sol-gel glasses: a new material for solar fluorescent planar concentrators?" Solar Energy Materials, vol. 21, no. 2-3, pp. 151-164, 1990.

[37] J. Roncali and F. Garnier, "Photon-transport properties of luminescent solar concentrators: analysis and optimization," Applied Optics, vol. 23, no. 16, pp. 2809-2817, 1984.

[38] T. Markvart, Solar Electricity, John Wiely \& Sons, New York, NY, USA, 1994.

[39] M. S. Al-Ayed, A. M. Al-Dhafiri, and M. B. Mahfoodh, "Global, direct and diffuse solar irradiance in Riyadh, Saudi Arabia," Renewable Energy, vol. 14, no. 1-4, pp. 249-254, 1998.

[40] M. S. De Cardona, M. Carracosa, F. Meseguer, F. Cusso, and F. Jaque, "Outdoor evaluation of luminescent solar concentrator prototypes," Applied Optics, vol. 24, no. 13, pp. 2028-2032, 1985.

[41] A. F. Mansour, M. G. El-Shaarawy, S. M. El-Bashir, M. K. El-Mansy, and M. Hammam, "A qualitative study and field performance for a fluorescent solar collector," Polymer Testing, vol. 21, no. 3, pp. 277-281, 2002.

[42] M. G. El-Shaarawy, S. M. El-Bashir, M. Hammam, and M. K. El-Mansy, "Bent fluorescent solar concentrators (BFSCs): spectroscopy, stability and outdoor performance," Current Applied Physics, vol. 7, no. 6, pp. 643-649, 2007.

[43] M. Iqbal, An Introduction to Solar Radiation, Academic Press, New York, NY, USA, 1983.

[44] A. Z. Sahin, A. Aksakal, and R. Kahraman, "Solar radiation availability in the northeastern region of Saudi Arabia," Energy Sources, vol. 22, no. 10, pp. 859-864, 2000.

[45] K. Ulgen, “Optimum tilt angle for solar collectors," Energy Sources A, vol. 28, no. 13, pp. 1171-1180, 2006.

[46] E. O. Falayi, A. B. Rabiu, and R. O. Teliat, "Correlations to estimate monthly mean of daily diffuse solar radiation in some selected cities in Nigeria," Advances in Applied Science Research, vol. 2, no. 4, pp. 480-490, 2011.

[47] Z. Aljarboua, "The national energy strategy for Saudi Arabia," World Academy of Science, Engineering and Technology, vol. 57, pp. 501-510, 2009. 

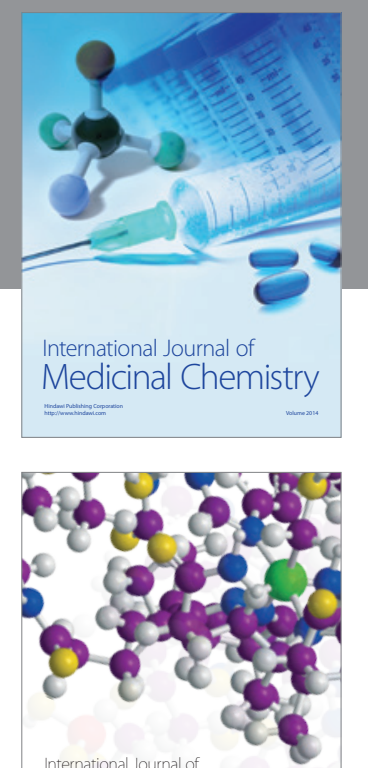

\section{Carbohydrate} Chemistry

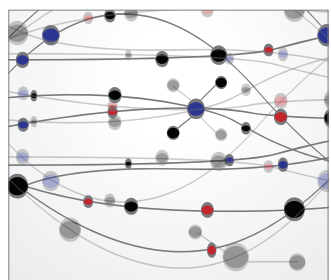

The Scientific World Journal
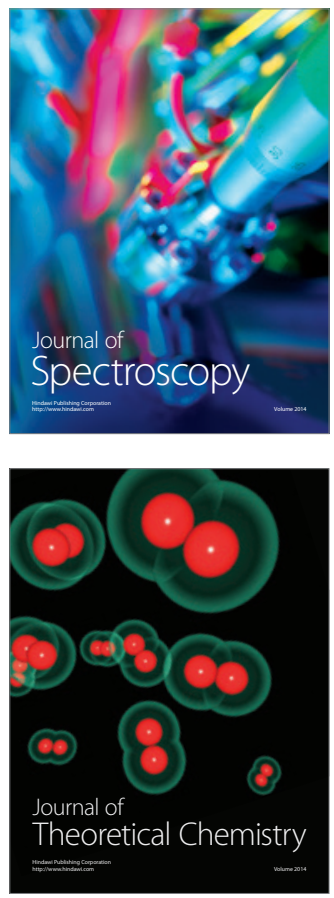
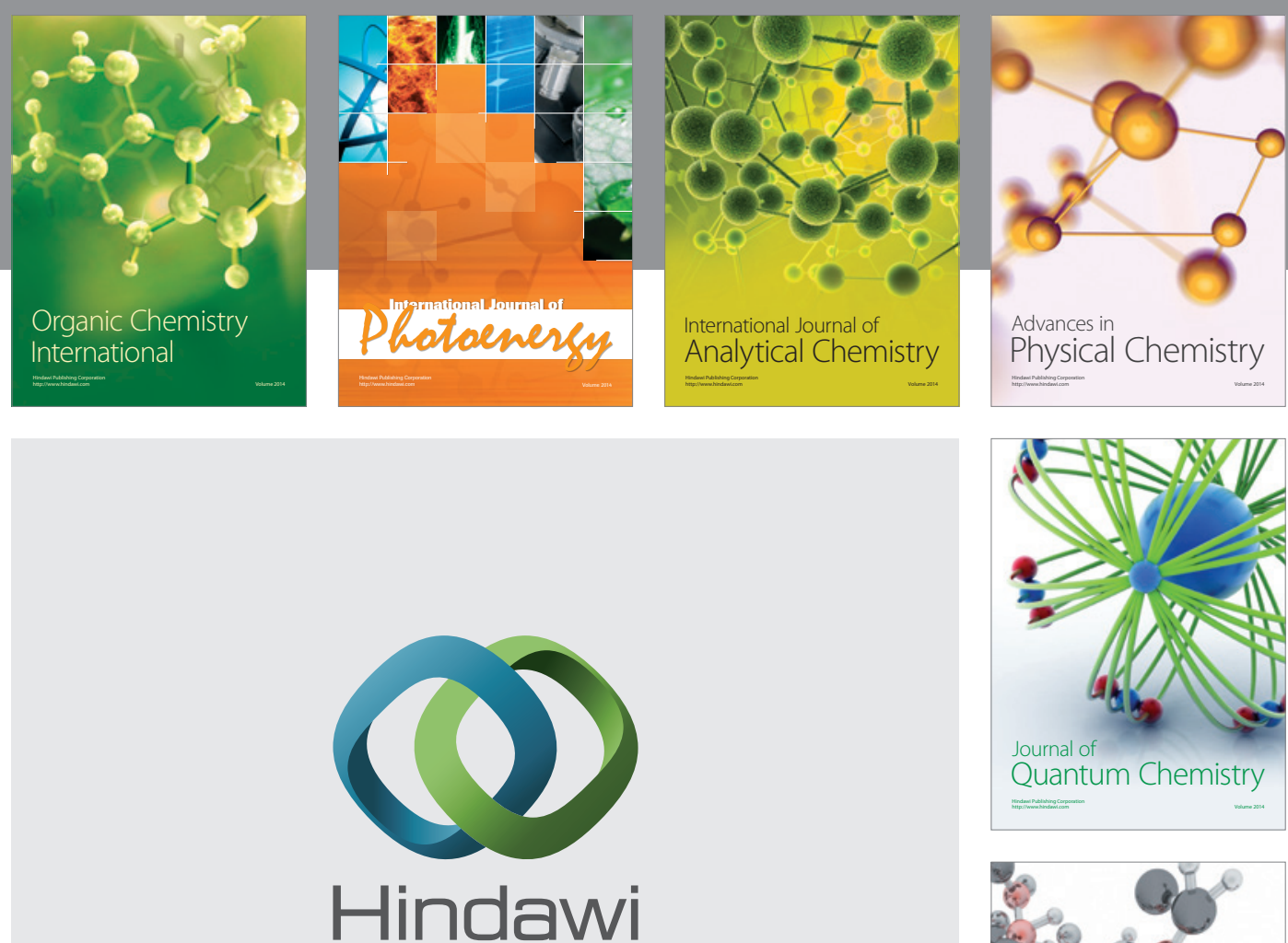

Submit your manuscripts at

http://www.hindawi.com

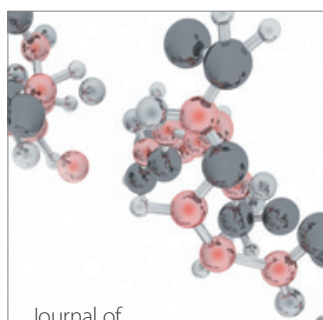

Analytical Methods

in Chemistry

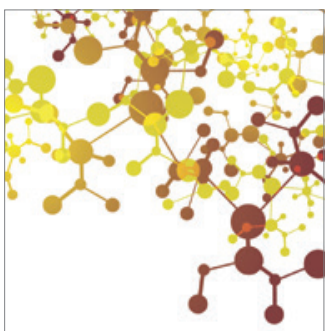

Journal of

Applied Chemistry



Inorganic Chemistry
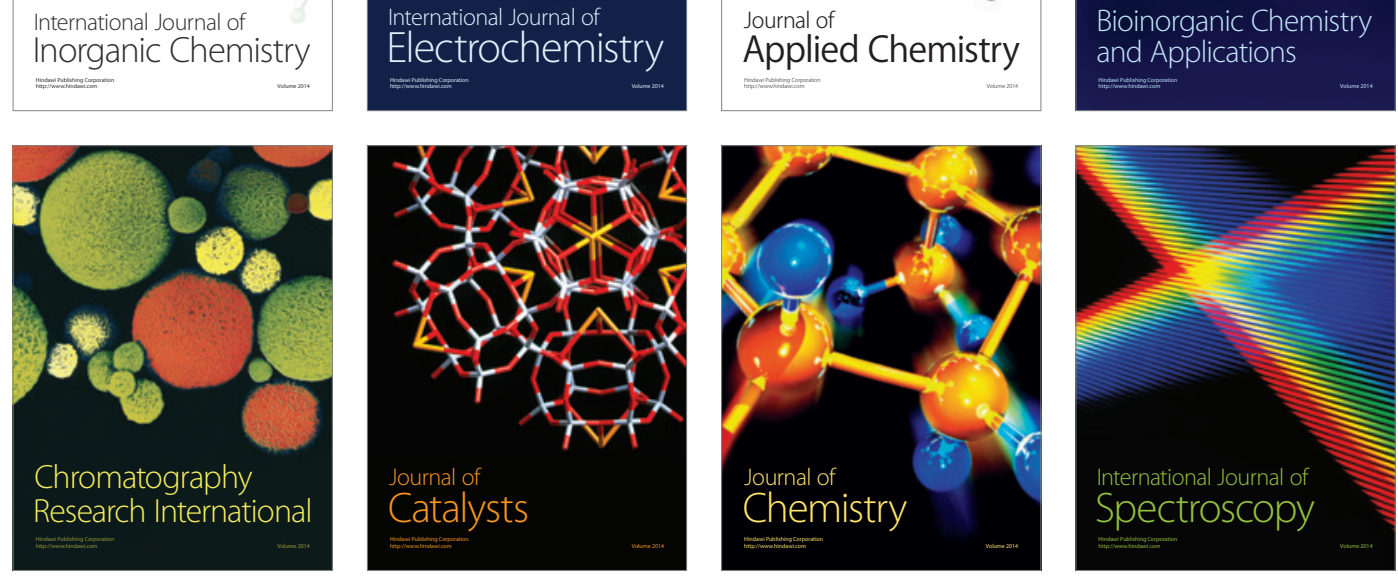